\title{
SINTESIS ASAM DIMER DARI MINYAK BUNGA MATAHARI DENGAN REAKSI DIELS-ALDER UNTUK MENGHASILKAN BAHAN BAKU SELF-HEALING RUBBER
}

\author{
Dimer Acid Synthesis from Sunflower Oil by Using Diels-Alder Reaction \\ to Produce Raw Material for Self-Healing Rubber
}

\author{
Mili PURBAYA ${ }^{1)}$, Hussin Mohd NOR ${ }^{2)}$, dan Didin SUWARDIN ${ }^{11}$ \\ ${ }^{1)}$ Balai Penelitian Sembawa - Pusat Penelitian Karet \\ Jl. Raya Palembang - Betung, Km.29, Palembang, 30001 \\ E-mail : irri_sbw@yahoo.com
}

${ }^{2}$ Faculty of Chemical Engineering - Universiti Teknologi Malaysia

Diterima: 24 Desember 2014 / Direvisi: 15 Februari 2015 / Disetujui: 10 April 2015

\begin{abstract}
Dimer acid synthesis from sunflower oil was performed by using the Diels-Alder reaction. This reaction was carried out by reacting linoleic acid from sunflower oil with acrylic acid. The resulting product was expected to be used for the synthesis of self-healing rubber. This rubber had ability to re-joint after tearing into parts. The DielsAlder reaction was confirmed by nuclear magnetic resonance (NMR) and infrared spectroscopy. It was found that carbon double bond in linoleic acid was attached by acrylic acid to yield dimer acid. This reaction was confirmed by appearing a broad peak in infra red spectra at range $3600-2300 \mathrm{~cm}^{-1}$. This peak represented hydrogen bond in dimer acid. Moreover, NMR result also showed the dimer acid forming at peak $173.3 \mathrm{ppm}$. This NMR peak represented carbon in carboxylic acid functional groups (- $\mathrm{COOH})$.
\end{abstract}

Keywords: Sunflower oil, dimer acid, self-healing rubber, NMR, infrared

\section{Abstrak}

Sintesis asam dimer yang bersumber dari minyak bunga matahari telah dilakukan dengan menggunakan reaksi Diels-Alder. Reaksi ini dilakukan dengan mereaksikan asam linoleat yang terkandung di dalam minyak bunga matahari dengan asam akrilat. Hasil reaksi diharapkan dapat digunakan untuk sintesis self healing rubber. Karet ini memiliki kemampuan untuk dapat tersambung kembali setelah diputuskan menjadi beberapa bagian. Reaksi Diels-Alder dikonfirmasi dengan melakukan analisis nuclear magnetic resonance (NMR) dan infra merah spektroskopi. Hasil reaksi menunjukkan bahwa ikatan rangkap karbon di dalam asam linoleat bereaksi dengan asam akrilat untuk menghasilkan asam dimer. Reaksi ini dikonfirmasi dengan munculnya sebuah puncak infra merah yang cukup luas pada kisaran 3600 $2300 \mathrm{~cm}^{-1}$. Puncak ini mewakili ikatan hidrogen yang terbentuk dalam asam dimer. Hasil analisis karbon NMR juga menunjukkan pembentukan asam dimer pada puncak 173,2 ppm. Puncak NMR ini mewakili karbon yang berada di dalam gugus fungsional asam karboksilat (- $\mathrm{COOH})$.

Kata kunci: Minyak bunga matahari, asam dimer, self-healing rubber, NMR, infra merah

\section{PENDAHULUAN}

Asam dimer yang berasal dari minyak nabati biasanya digunakan untuk surfaktan, pelapis (coatings), perekat (adhesives), sabun, detergen, dan inhibitor korosi (Jevne dan Schwebke, 1979; Kadesch, 1979; Tramount dan Charleston, 1992; dan Robinson, 1992), sedangkan aplikasi asam dimer untuk bidang elastomer belum banyak dilakukan. Hanya penemuan sekelompok peneliti yaitu Cordier et al (2008), Montarnal et al (2008-2010), dan Tournilhac et al (2010) yang berhasil menemukan elastomer baru yang disebut self-healing rubber.

Elastomer baru ini memiliki sifat healing ability yaitu kemampuan elastomer untuk dapat memperbaiki diri sendiri setelah mengalami kerusakan. Dengan adanya sifat ini, karet yang telah dipotong menjadi dua bagian, dapat disatukan kembali dengan menekan kedua potongan yang telah terputus tersebut. Setelah 
tersambung, karet tersebut tetap memiliki sifat elastis seperti sifat karet pada umumnya (Gambar 1).

Sifat healing ability ini tidak dimiliki oleh karet alam maupun karet sintesis. Padahal, sifat baru ini dapat dikembangkan dan diaplikasikan untuk menghasilkan produk-produk baru yang memberi manfaat bagi perkembangan industri karet dan elastomer.

Self healing rubber diperoleh melalui dua tahap sintesis, yaitu pembuatan oligoamida yang berasal dari asam dimer/trimer dan oligoamida yang diperoleh

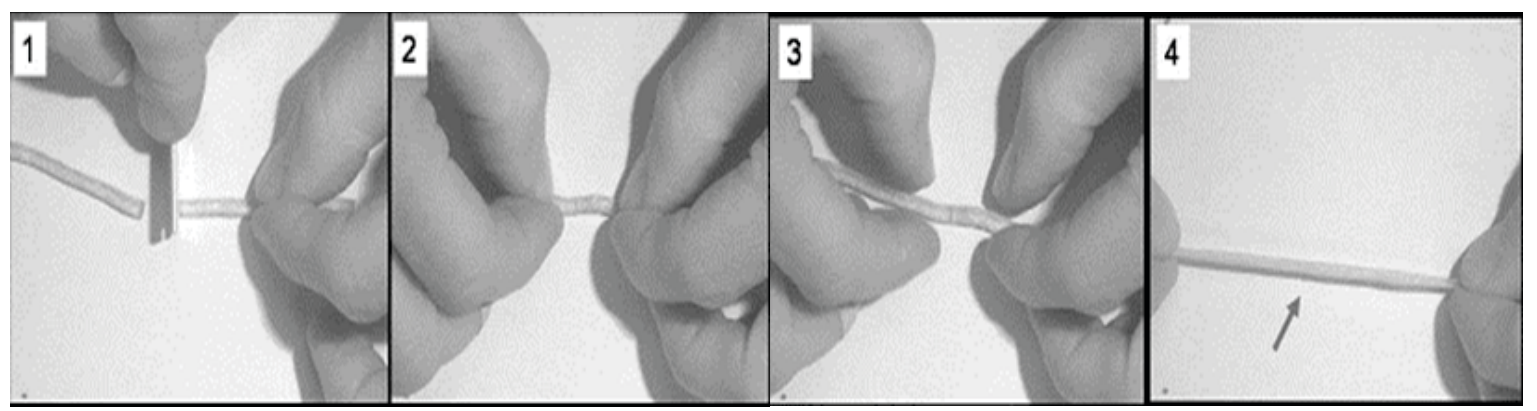

Gambar 1. Self-healing rubber (1) memotong, (2) mempertemukan, (3) memperbaiki, dan (4) meregangkan (Zhang dan Rong, 2011)

Figure 1. Self-healing rubber (1) cut, (2) join, (3) mend, and (4) stretch (Zhang and Rong, 2011)

kemudian disintesis menjadi self-healing rubber. Asam dimer/trimer yang digunakan untuk pembuatan elastomer ini adalah Empol 1016. Bahan kimia ini sulit diperoleh terutama di Indonesia karena harus diimpor dari luar negeri. Untuk pengembangan produk self-healing rubber, perlu dicari alternatif asam dimer baru yang berpotensi menjadi bahan baku pembuatan elastomer baru yang memiliki sifat healing ability.

Dalam penelitian ini, telah dicoba sintesis asam dimer yang berasal dari minyak bunga matahari. Minyak bunga matahari mengandung asam lemak tidak jenuh yang cukup tinggi, yaitu $31,5 \pm 4,5$ asam oleat dan 59,5 \pm 7,5 asam linoleat (Kostik et al., 2013). Tingginya kandungan asam lemak tidak jenuh di dalam minyak bunga matahari memungkinkannya menjadi sumber utama pembuatan elastomer dengan terlebih dahulu merubah asam lemak tidak jenuh ini menjadi asam dimer.

Beberapa peneliti telah melakukan pembuatan asam dimer dengan menggunakan reaksi Diels-Alder (Gambar 2). Tramount dan Charleston (1992) dan Ward (1973) telah membuat asam dimer dengan mereaksikan asam linoleat dengan asam akrilat dan katalis iodin, sedangkan Jevne dan Schwebke (1979) menggunakan katalis yang berbeda, yaitu bentonit. Sementara Cosgrove (1991) membuat asam dimer tanpa bantuan katalis tetapi memerlukan suhu reaksi yang lebih tinggi .

Penelitian asam dimer yang telah dilakukan semuanya berasal dari tall oil (produk sampingan dari pengolahan kayu), sedangkan sintesis asam dimer yang berasal dari minyak bunga matahari belum banyak dilakukan, sehingga dilakukanlah sintesis asam dimer yang berasal dari minyak bunga matahari. Sintesis asam dimer dilakukan dengan mereaksikan asam linoleat dari minyak bunga matahari dengan asam akrilat dengan bantuan katalis iodin. Asam dimer yang diperoleh kemudian dianalisa struktur molekulnya dengan analisis infra merah dan NMR.

\section{BAHAN DAN METODE}

Penelitian dilaksanakan di Laboratorium Polimer Universiti Teknologi Malaysia (UTM) pada bulan September 2012. Bahan utama pembuatan asam dimer adalah minyak bunga matahari (Everest). Komposisi minyak bunga matahari adalah $65 \%$ asam linoleat, 25\% asam oleat dan 10\% asam lemak jenuh. Bahan kimia yang 


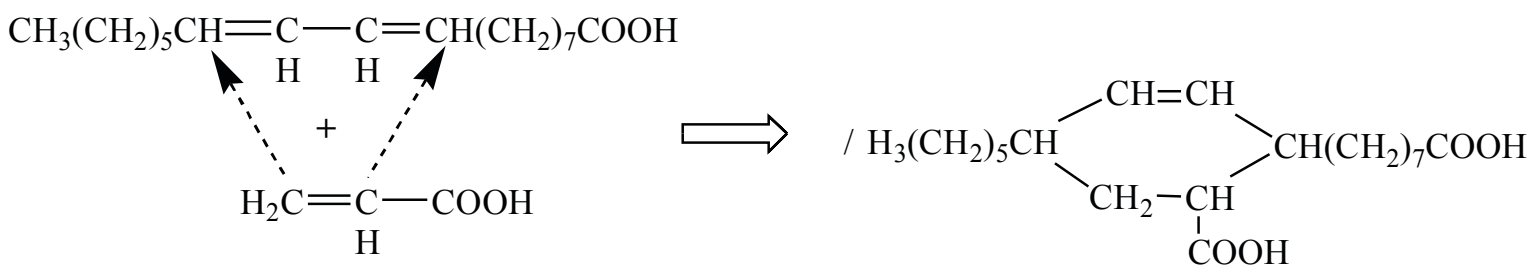

Gambar 2. Mekanisme reaksi pembentukan asam dimer dengan menggunakan reaksi DielsAlder (Kadesch, 1979)

Figure 2. Reaction mechanism of the formation of dimer acid by using Diels-Alder reaction (Kadesch, 1979)

digunakan adalah asam akrilat (Merck) dan katalis iodin (Comak). Peralatan yang digunakan untuk sintesis dapat dilihat pada Gambar 3.

\section{Sintesis Asam Dimer}

Minyak bunga matahari sebanyak $300 \mathrm{~g}$ dicampurkan dengan iodin 0,298 g di dalam labu reaksi berukuran 1 liter. Campuran dalam labu reaksi selanjutnya direfluks pada suhu $250{ }^{\circ} \mathrm{C}$. Pada saat suhu campuran mencapai $230{ }^{\circ} \mathrm{C}, 44$ gram asam akrilat ditambahkan setetes demi setetes ke dalam campuran. Reaksi dilakukan selama 2 jam. Setelah reaksi selesai, campuran didinginkan pada suhu kamar.

\section{Analisis Infra Merah}

Analisis infra merah dilakukan untuk mengetahui gugus fungsional yang terkandung di dalam minyak bunga matahari sebelum dan setelah reaksi DielsAlder. Analisis ini menggunakan Perkin Elmer spektrum 2000 FTIR. Persiapan contoh dilakukan dengan menuangkan satu tetes sampel (minyak bunga matahari sebelum reaksi Diels-Alder dan minyak bunga matahari setelah reaksi Diels-Alder) diantara dua piringan disk $\mathrm{KBr}$ (kalium bromida), kemudian diukur spektrumnya dengan FTIR.

\section{Analisis NMR}

Analisis NMR dilakukan untuk mengetahui struktur kimia minyak bunga matahari sebelum dan setelah reaksi DielsAlder. Analisis dilakukan dengan menggunakan Bruker Avance II NMR at high field spectrometer $(400 \mathrm{MHz})$. Sebelum dilakukan analisis, sampel dilarutkan terlebih dahulu di dalam larutan $\mathrm{CDCl}_{3}$ (kloroform terdeutrasi).

\section{HASIL DAN PEMBAHASAN}

\section{Sintesis Asam Dimer}

Sintesis asam dimer dilakukan dengan menggunakan reaksi Diels-Alder. Dalam reaksi ini, ikatan rangkap karbon-

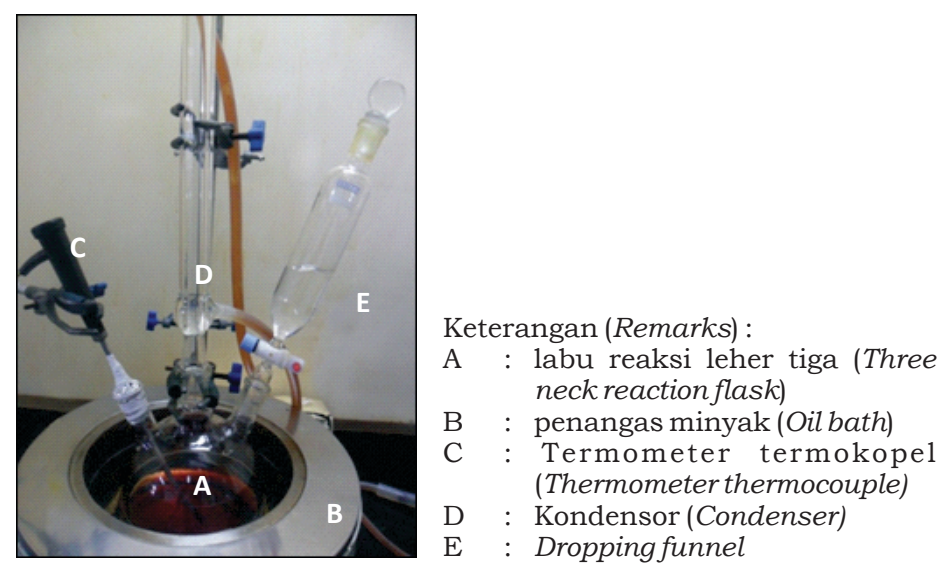

Gambar 3 . Reaktor asam dimer

Figure 3. Dimer acid reactor 
karbon pada asam akrilat akan bereaksi dengan dua ikatan rangkap pada asam linoleat membentuk asam dimer yang memiliki dua gugus fungsional asam karboksilat $(\mathrm{COOH})$. Reaksi ini dilakukan dengan bantuan katalis iodin. Katalis iodin berfungsi sebagai isomerizing agent (Kadesch, 1979), yaitu mengubah asam linoleat 9,12 berisomer menjadi 10,12 atau 9,11 as a m linoleat, sehingga memungkinkan terjadinya reaksi DielsAlder.

Tahapan sintesis diawali dengan mencampur minyak bunga matahari dengan katalis iodin membentuk campuran yang berwarna merah. Campuran ini kemudian dipanaskan sampai suhu $250^{\circ} \mathrm{C}$. Pada saat suhu campuran mencapai $122^{\circ} \mathrm{C}$, warna merah pada campuran akan menghilang, sehingga campuran menjadi jernih. Perubahan warna ini menandakan bahwa asam linoleat telah berisomer menjadi 10,12 atau 9,11 asam linoleat. Kemudian, pada saat suhu campuran mencapai $230^{\circ} \mathrm{C}$, asam akrilat ditambahkan setetes demi setetes pada campuran tersebut. Penambahan asam akrilat dilakukan secara bertahap untuk menghindari terjadinya polimerisasi karena asam akrilat merupakan asam yang sangat reaktif dan mudah bereaksi membentuk polimer. Setelah reaksi selesai akan diperoleh asam dimer (Gambar 4) dengan derajat keasaman $(\mathrm{pH})$ sebesar 4.

Minyak bunga matahari mengandung asam oleat dan asam lemak jenuh dengan komposisi yang relatif sedikit dibandingkan dengan asam linoleat. Dalam reaksi Diels-Alder, asam akrilat tidak dapat bereaksi dengan asam oleat karena asam oleat hanya mengandung satu ikatan rangkap karbon, serta tidak dapat bereaksi dengan asam lemak jenuh karena asam lemak jenuh tidak memiliki ikatan rangkap, sehingga kemungkinan terjadinya reaksi samping sangat kecil. Tetapi berdasarkan penelitian yang telah dilakukan oleh Tramount dan Carleston (1992) bahwa reaksi Diels-Alder pada Tall oil menghasilkan produk samping berupa C-21 lactone. Tetapi pada kurva infra merah hasil reaksi DielsAlder dari minyak bunga matahari, tidak ditemukan puncak $\beta$ lactone. Puncak $\beta$ lactone ini biasanya muncul pada 1840 $1815 \mathrm{~cm}^{-1}$ (Socrates, 1994).

\section{Analisis Infra Merah}

Gambar 5 menyajikan kurva infra merah spektrum dari minyak bunga matahari sebelum dan setelah reaksi DielsAlder. Identifikasi spektrum infra merah dilakukan berdasarkan absorpsi asam dimer yang telah umum diketahui (Socrates, 1994; Silverstein dan Bassler, 1967). Identifikasi puncak-puncak infra merah ini juga didukung oleh beberapa penelitian sebelumnya mengenai minyak nabati (Alexa et al., 2009; Vlachos et al., 2006; serta Rohman dan Man, 2012) dan asam dimer (Golubev dan Denisov, 1982; Florio et al., 2003; dan Millikan dan Pitzer, 1958).

Kurva infra merah minyak bunga matahari setelah reaksi Diels-Alder hampir sama dengan kurva infra merah minyak bunga matahari sebelum reaksi Diels-Alder, tetapi ada beberapa puncak yang terbentuk yang menandakan bahwa reaksi Diels-Alder telah terjadi. Sebuah puncak yang lebar (broad peak) pada kisaran $3600-2300 \mathrm{~cm}^{-1}$ pada grafik spektrum minyak bunga matahari setelah reaksi Diels-Alder

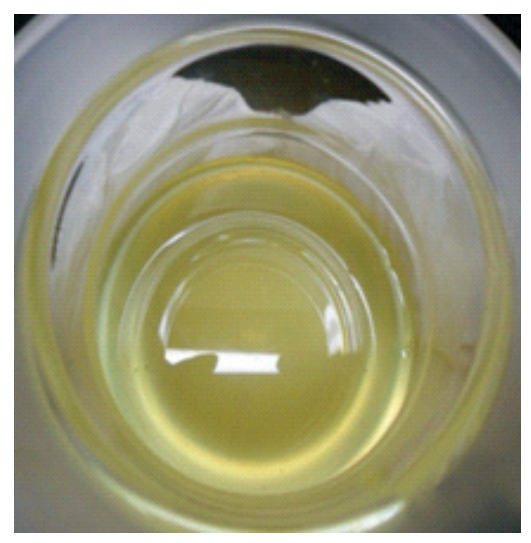

Gambar 4. Asam dimer dari minyak bunga matahari

Figure 4. Dimer acid from sunflower oil 

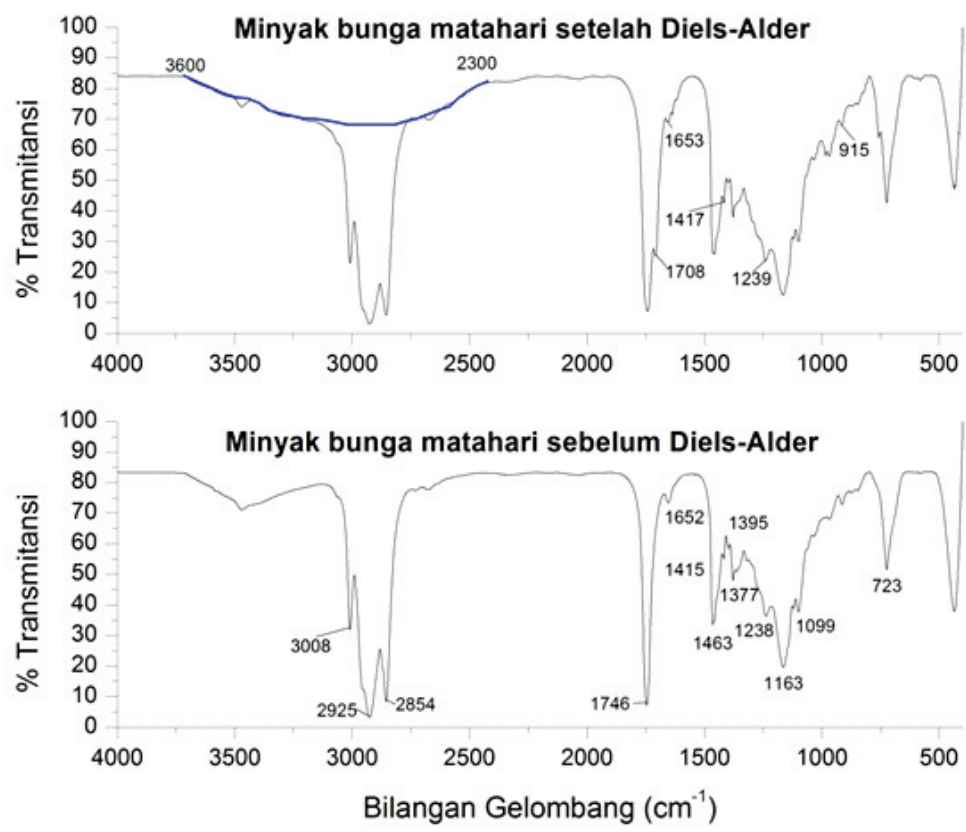

Gambar 5. Perbandingan FTIR spektra minyak bunga matahari sebelum dan setelah reaksi Diels-Alder

Figure 5. FTIR comparison between sunflower oil before and after Diels-Alder reaction

merupakan ikatan hidrogen pada asam dimer. Puncak ini tidak terlihat jelas karena overlapping dengan puncak-puncak alkil yang terdapat pada gliserida, yaitu puncak 3008,2924 dan $2855 \mathrm{~cm}^{-1}$.

Sebuah puncak infra merah muncul pada $1653 \mathrm{~cm}^{-1}$ pada grafik spektrum minyak bunga matahari setelah reaksi DielsAlder mewakili ikatan rangkap karbonkarbon yang terdapat dalam struktur asam dimer. Tinggi puncak ini terlihat lebih rendah dibandingkan dengan hasil spektrum minyak bunga matahari sebelum reaksi Diels-Alder pada puncak yang sama. Hal ini menunjukkan bahwa ikatan rangkap pada struktur minyak bunga matahari setelah reaksi Diels-Alder telah berkurang akibat dari reaksi Diels-Alder antara asam akrilat dan minyak bunga matahari.

Sebuah puncak baru muncul pada spektrum minyak bunga matahari setelah reaksi Diels-Alder yaitu pada bilangan gelombang $1708 \mathrm{~cm}^{-1}$. Puncak ini mewakili $\mathrm{C}=\mathrm{O}$ stretching gugus fungsional asam dikarboksilat. Hasil ini didukung oleh hasil penelitian terdahulu mengenai asam karboksilat dimer (Golubev dan Denisov, 1982).
Vibrasi bending $\mathrm{O}-\mathrm{H}$ pada minyak bunga matahari setelah reaksi Diels-Alder terdeteksi pada puncak 1417 dan $915 \mathrm{~cm}^{-1}$. Hasil ini mendekati hasil dari penelitian terdahulu tentang asam dimer dari asam format, yaitu terdapatnya puncak $1415 \mathrm{~cm}^{-1}$ (Florio et al., 2003) dan $917 \mathrm{~cm}^{-1}$ (Millikan dan Pitzer, 1958) pada asam format dimer, dimana kedua puncak ini mewakili vibrasi gugus fungsional $\mathrm{OH}$ bending dari asam format dimer. Sebuah puncak pada $1239 \mathrm{~cm}$ ${ }^{1}$ pada spektrum minyak bunga matahari setelah reaksi Diels-Alder merupakan $\mathrm{C}-\mathrm{O}$ stretching gugus fungsional asam dikarboksilat (Purbaya et al., 2013).

\section{Analisa NMR}

Gambar 6 dan 7 menyajikan karbon dan proton spektrum NMR dari minyak bunga matahari setelah reaksi Diels-Alder serta perkiraan struktur asam dikarboksilat yang terbentuk. Struktur yang terbentuk menunjukkan bahwa bukan hanya gugus fungsional asam karboksilat yang terdapat di dalam asam dimer, tetapi ada juga struktur trigliserida yang masih berada dalam struktur asam dimer. Struktur trigliserida merupakan komponen utama penyusun minyak bunga matahari. 


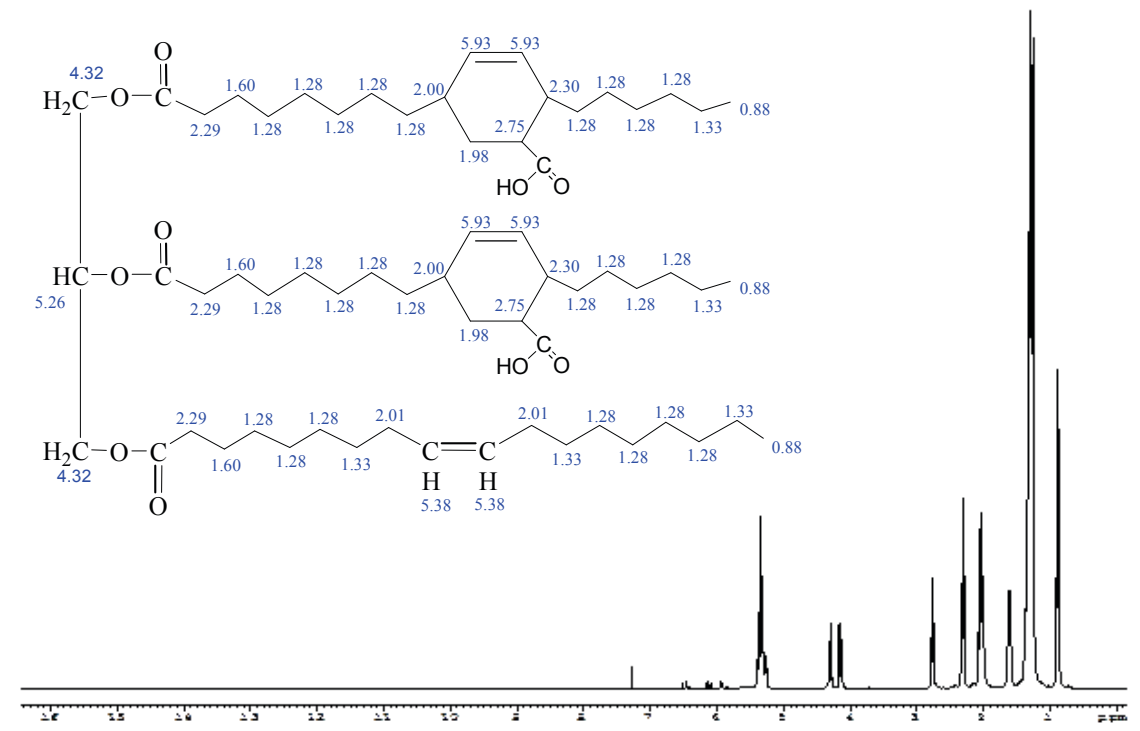

Gambar 6. Proton NMR Spektrum minyak bunga matahari setelah reaksi Diels-Alder Figure 6. Proton NMR of sunflower oil Spectrum after Diels-Alder reaction

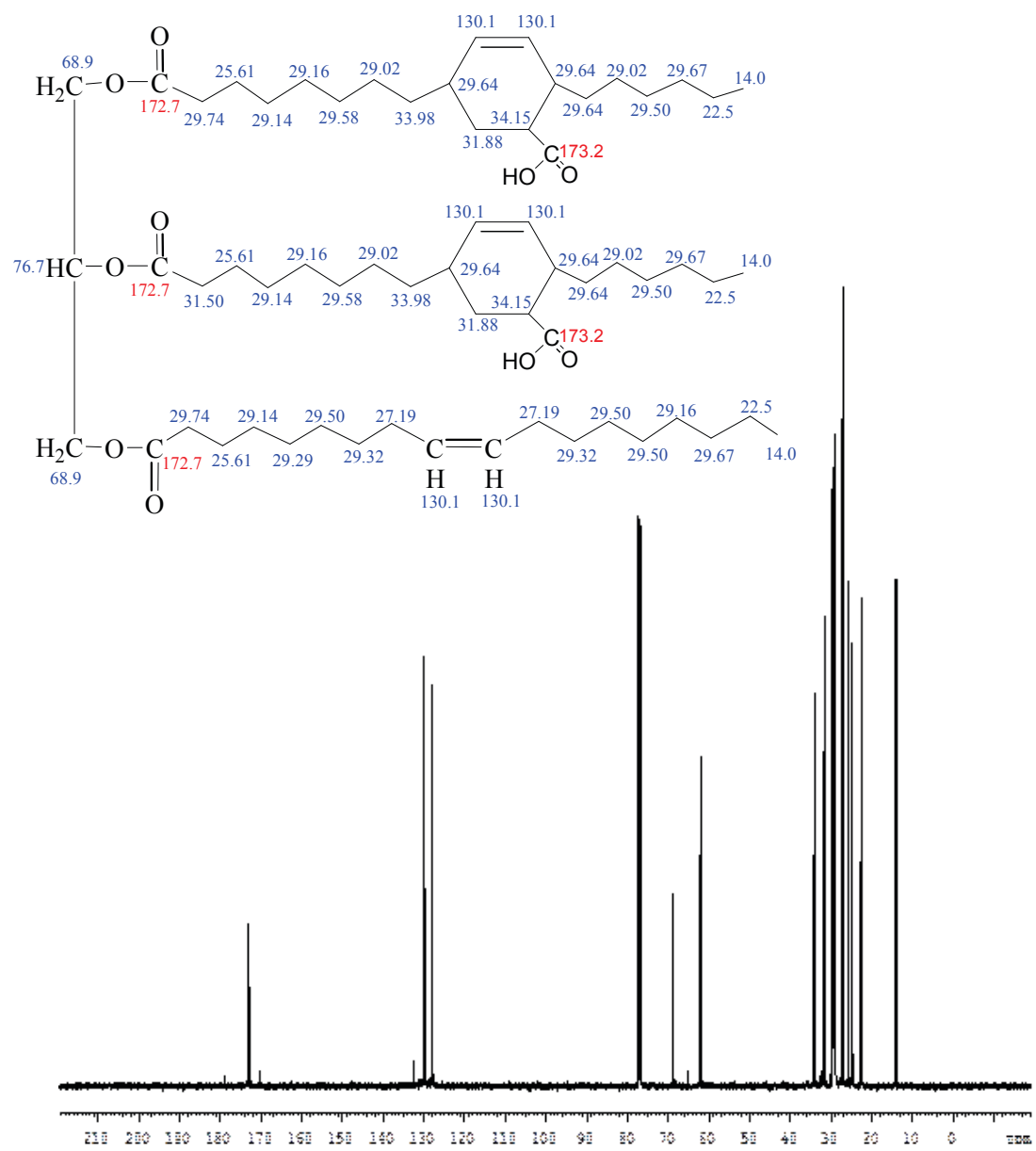

Gambar 7. Karbon NMR Spektrum minyak bunga matahari setelah reaksi Diels-Alder Figure 7. Carbon NMR of sunflower oil Spectrum after Diels-Alder reaction 
Gugus fungsional asam karboksilat seharusnya muncul pada 10,5 - 12 ppm pada proton NMR dan 170 - 185 ppm pada karbon NMR. Tetapi pada penelitian ini, tidak diperoleh puncak proton NMR yang menandakan adanya proton gugus fungsional asam karboksilat disebabkan adanya pertukaran proton. Sedangkan puncak karbon gugus fungsional asam karboksilat muncul pada $173,2 \mathrm{ppm}\left(-\mathrm{CH}_{2}-\right.$ $\left.\mathrm{O}-\underline{\mathrm{CO}}-\mathrm{CH}_{2}-\right)$ dan 172,7 ppm (-CH-C $\left.\mathrm{C}-\mathrm{OH}\right)$.

Puncak-puncak proton NMR pada 2,$00 ; 5,93 ; 2,30 ; 1,98$; dan 2,75 ppm mewakili proton-proton yang terdapat dalam cincin aromatik yang terbentuk karena reaksi Diels-Alder. Karbon-karbon pada cincin aromatik diwakilkan oleh puncakpuncak 20,64;130,1;31,88 and 34,5 ppm pada grafik karbon NMR.

\section{KESIMPULAN DAN SARAN}

Hasil analisis infra merah dan NMR menunjukkan bahwa asam dikarboksilat terbentuk pada gugus trigliserida dari minyak bunga matahari. Hal ini menunjukkan bahwa gugus asam dimer dari minyak bunga matahari telah berhasil diperoleh dengan menggunakan reaksi Diels-Alder. Asam dimer yang berasal dari minyak bunga matahari ini berpotensi menjadi bahan utama untuk pembuatan self-healing rubber.

Penelitian lebih lanjut akan dilaksanakan untuk menganalisa persentasi keberhasilan reaksi Diels-Alder, meningkatkan jumlah gugus asam dimer dan proses purifikasinya.

\section{DAFTAR PUSTAKA}

Alexa, E., A. Dragomirescu, G. Pop, C. Jianu, and D. Dragos. 2009. The Use of FTIR Spectroscopy in the Identification of Vegetable Oils Adulteration. Journal of Food, Agriculture \& Environment 7(2) : 20-24.

Barrett, F. O., C. G. Goebel. and R. M. Peters. 1957. Process of Dimerizing Monounsaturated Fatty Acids. U.S. Patent No. 2,793,219.
Cordier, P., F. Tournilhac, C. SouliéZiakovic, and L. Leibler. 2008. SelfHealing and Thermoreversible Rubber from Supramolecular Assembly. Nature 451 : 977-980.

Cosgrove, J. P. 1991. Process for Making a Dicarboxylic Acid. U. S. Patent No. $5,053,534$.

Florio, G. M., T. S. Zwier, E. M. Myshakin, K. D. Jordan, and E. L. Sibert III. 2003. Theoretical Modeling of the $\mathrm{OH}$ Stretch Infrared Spectrum of Carboxylic Acid Dimers Based on First-Principles Anharmonic Couplings. Journal of Chemicals Physics 118(4) : 1735 1746 .

Golubev, N. S. and G. S. Denisov . 1982. Spectra and Structure of Asymmetric Carboxylic Acid Dimers in Solution. Journal of Applied Spectroscopy 37(2): 930-936.

Harwood, H. J. 1962. Reactions of The Hydrocarbon Chain of Fatty Acids. Chemical Reviews. 62(2) : 99-154.

Jevne, A. H. and G. L. Schwebke. 1979 Preparation of $\mathrm{C}_{21}$ Dicarboxylic Acid. U.S Patent No. 4, 156,095.

Kadesch, R. G. 1979. Fat-based Dibasic Acid. Journal of the American Oil Chemists Society 56 (11) : 845A-849A.

Kostik, V., S. Memeti and B. Bauer. 2013. Fatty acid Composition of Edible Oils and Fats. Journal of Hygienic Engineering and Design 4: 112-116.

Millikan, R. C. and K. S. Pitzer. 1958. The Infrared Spectra of Dimeric and Crystalline Formic Acid. Journal of the American Chemical Society 80 (14): $3515-3521$.

Montarnal, D., P. Cordier, C. SouliéZiakovic, F. Tournilhac, and L. Leibler. 2008. Synthesis of Self-Healing Supramolecular Rubbers from Fatty Acid Derivatives, Diethylene Triamine, and Urea. Journal of Polymer Science. Part A : Polymer Chemistry 46(24): 7925-7936. 
Montarnal, D., F. Tournilhac, M. Hidalgo, J. L. Couturier, and L. Leibler. 2009. Versatile One-Pot Synthesis of Supramolecular Plastics and SelfHealing Rubbers. Journal of The American Chemical Society 131 (23): 7966-7967.

Montarnal, D., F. Tournilhac, M. Hidalgo, and L. Leibler. 2010. Epoxy-Based Networks Combining Chemical and Supramolecular Hydrogen-Bonding Crosslinks. Journal of Polymer Science Part A : Polymer Chemistry 48(5): 11331141.

Patrick, P. D. Jr., S. Windermere, and S. C. Charleston. 1964. Treatment of Tall oil Fatty Acids. U.S. Patent No. 3, 157,629.

Purbaya, M., H. M. Nor and D. Suwardin. 2013. Synthesis of Sunflower Oil Based Elastomer and Its Characterization by Using Spectroscopic Techniques. HPI-FAPS International Conference on Innovation in Polymer Science and Technology. Yogyakarta, 7-10 Oktober.

Robinson, P. L. 1992. C-21 Dicarboxylic acids in Soap and Detergent Application. Journal of the American Oil Chemists Society 69 (1): 52-59.

Rohman, A., and Y. B. C. Man. 2012. Quantification and Classification of Corn and Sunflower Oils as Adulterants in Olive Oil Using Chemometrics and FTIR Spectra. The Scientific World Journal. V2012. DOI: $10.1100 / 2012 / 250795$. www.ncbi.nlm.nih.gov diakses tanggal 13 November 2012.
Silverstein, R. M. and G. C. Bassler. 1967. Spectrometric Identification of Organic Compounds. John Wiley and Sons, Inc., New York.

Socrates, G. 1994. Infrared Characteristic Group Frequencies. John Wiley \& Sons, Chichester.

Tramount, Y. A. and S. C. Charleston. 1992. Method for Production of Dicarboxylic Acid and Lactone. U.S. Patent No. 5, 136,055.

Tournilhac, F., P. Cordier, D. Montarnal, C. S. Ziakovic, and L. Leibler. 2010. SelfHealing Supramolecular Networks. Macromolecular Symposia 291-292(1) : 84-88.

Vlachos, N., Y. Skopelitis, M. Psaroudaki, V. Konstantinidou, A. Chatzilazarou, and E. Tegou. 2006. Applications of Fourier Transform-Infrared Spectroscopy to Edible Oils. Analytica Chimica Acta. 573-574: 459-465.

Ward, B. F. 1973. Selective Reaction of Fatty Acids and Their Separation. U. S Patent No. 3, 753, 968.

William, B. C. and S. Michael D. 2000. Process for Producing Light Color Dimer Acid from the Dimerization of Unsaturated Fatty Acids. Patent No. WO2000075252A1.

Zhang, M. Q. and M. Z. Rong. 2011. Selfhealing Polymers and Polymer Composites. New Jersey. John Wiley \& Sons, Inc. 